\title{
Ochrobactrum anthropi Bacteremia in a Child with Inborn Error of Mitochondrial Fatty Acid Oxidation
}

\author{
Nasser Yehia A. Aly ${ }^{a, b}$ Hadeel N. Salmeen ${ }^{b}$ Rajinder M. Joshi ${ }^{c}$ \\ a Department of Tropical Medicine and Hygiene, Faculty of Medicine, University of Alexandria, Alexandria, Egypt; \\ ${ }^{b}$ Directorate of Infection Control, Ministry of Health, and ' Department of Microbiology, YIACO Diagnostic Center, \\ Al-Adan Hospital, Kuwait
}

\section{Key Words}

Ochrobactrum anthropi $\cdot$ Bacteremia - Mitochondrial fatty acid oxidation

\begin{abstract}
Objective: To report an incident of bacteremia caused by Ochrobactrum anthropi. Case Presentation and Intervention: The case of a female child aged 2 years and 10 months with a known history of long-chain 3-hydroxyacyl-coenzyme A dehydrogenase deficiency who developed $O$. anthropi bacteremia during hospital stay is presented. Patient's history, clinical findings, laboratory and radiological investigations were thoroughly reviewed. The cultured organism was identified using MicroScan WalkAway 96 SI (Dade Behring) as well as by conventional techniques. Imipenem resistance was confirmed by the conventional Kirby-Bauer disk diffusion technique on Muller-Hinton agar with no zone of inhibition around a 10- $\mu$ g imipenem disk (Hi Media) using the $0.5 \mathrm{McFarland}$ standard. Conclusion: This report shows 0 . anthropi as a rare nosocomial pathogen that affected a patient who was immunocompromised. The O.anthropi showed multidrug resistance. Copyright $\odot 2007$ S. Karger AG, Basel
\end{abstract}

\section{Introduction}

Ochrobactrum anthropi, formerly known as Centers for Disease Control and Prevention group Vd or Achromobacter group Vd, is a nonfastidious, Gram-negative, motile, nonfermenting bacillus with strict oxidative metabolism that possesses a very active urease [1]. The organism has been isolated from different human clinical sources leading to its specific epithet anthropi [2]. However, nonhuman sources exist and include soil, hospital water sources, indwelling catheters, retained foreign bodies, and contaminated pharmaceuticals [3]. Although O. anthropi is an opportunistic pathogen in immunocompromised patients, it is increasingly being recognized to be a causative agent in healthy hosts [4]. Incidents of nosocomial bacteremia in children caused by this organism are very infrequent.

We report a case of $O$. anthropi bactermia in a child from Kuwait with an inborn error of mitochondrial fatty acid oxidation.

\section{Case Report}

The patient was a female child aged 2 years and 10 months with a known history of long-chain 3-hydroxyacyl-coenzyme A dehydrogenase (LCAD) deficiency, an inborn error of mitochondrial

\section{KARGER \\ Fax +41613061234 E-Mail karger@karger.ch} www.karger.com
(C) 2007 S. Karger AG, Basel

$1011-7571 / 07 / 0166-0463 \$ 23.50 / 0$

Accessible online at:

www.karger.com/mpp
Nasser Yehia A. Aly

Directorate of Infection Control, Ministry of Health

PO Box 12414

71655 Al-Shamiya (Kuwait)

Tel. +965 488 8000, ext. 3816, Fax +965 488 2684, E-Mail nasseryehia@gmail.com 
fatty acid oxidation. She was born to first-degree-related parents with a sibling who died at the age of 5 months and found to have LCAD deficiency.

The patient was admitted to the hospital on January 6, 2006. She had a fever, dyspnea, cough and a wheezy chest. On examination, she was conscious and responded to commands. Heart rate was 110 beats/min, blood pressure $120 / 80 \mathrm{~mm} \mathrm{Hg}$, temperature $38.5^{\circ} \mathrm{C}$, and respiratory rate $70 / \mathrm{min}$. Cardiac examination revealed cardiomegaly. Chest examination showed diminished air entry, expiratory wheezes and widespread scattered crackles. Abdominal examination revealed abdominal distension and hepatomegaly. Chest X-ray showed a picture of bronchopneumonia.

Laboratory investigation showed white blood cells $9.2 \times 10^{9} / 1$, red blood cells $4.41 \times 10^{12} / 1$, hemoglobin $104 \mathrm{~g} / \mathrm{l}$, platelets $297 \times$ $10^{9} / \mathrm{l}$, lactic acid $2.39 \mathrm{mmol} / \mathrm{l}$ (normal value $0.40-2 \mathrm{mmol} / \mathrm{l}$ ) and blood ammonia $109 \mu \mathrm{mol} / \mathrm{l}$ (normal value 11-32 $\mu \mathrm{mol} / \mathrm{l}$ ). In blood gas analysis, $\mathrm{pH}$ was 7.4, $\mathrm{HCO}_{3} 22 \mathrm{mmol} / \mathrm{l}$ and $\mathrm{SaO}_{2} 95 \%$. Creatine kinase was 4,012 U/l (normal value 21-232 U/l), C-reactive protein $8.95 \mathrm{mg} / \mathrm{l}$ (normal value $0.0-5 \mathrm{mg} / \mathrm{l}$ ), alanine aminotransferase $435 \mathrm{U} / \mathrm{l}$, aspartate transaminase 1,641 U/1, alkaline phosphatase $92 \mathrm{U} / \mathrm{l}$, total bilirubin $8.1 \mu \mathrm{mol} / \mathrm{l}$ (normal value 1.71 $17.1 \mu \mathrm{mol} / \mathrm{l}$ ) and blood glucose $4.2 \mathrm{mmol} / \mathrm{l}$ (normal value 3.9-6.1 $\mathrm{mmol} / \mathrm{l})$. Blood and urine cultures were negative. The child was treated empirically with intravenous cefotaxime and glucose.

Three days later, the child collapsed in the ward and blood gas analysis showed metabolic acidosis ( $\left.\mathrm{pH} 7.29, \mathrm{HCO}_{3} 12 \mathrm{mmol} / \mathrm{l}\right)$. The child received resuscitative measures. She was diagnosed as having cardiomyopathy that was confirmed by echocardiography. Antifailure treatment was commenced. Creatine kinase was $2,269 \mathrm{U} / 1$. The patient gradually improved and heart failure was under control. By day 34, the overall general condition improved and creatine kinase dropped to $89.9 \mathrm{U} / 1$

On February 15, 2006 (day 41), she had a fever $\left(40^{\circ} \mathrm{C}\right)$ and developed seizure with postictal drowsiness. Meningoencephalitis was suspected. CT was normal. Lumbar puncture was not performed due to the critical state of the patient. Chest examination was normal. Basic biochemical tests were within normal ranges and no evidence of metabolic encephalopathy was found. Laboratory investigations showed the following: white blood cells $7.5 \times$ $10^{9} / \mathrm{l}$, hemoglobin $97 \mathrm{~g} / \mathrm{l}$, platelets $279 \times 10^{9} / \mathrm{l}$, lactic acid 3.3 $\mathrm{mmol} / \mathrm{l}$, blood ammonia $35 \mu \mathrm{mol} / \mathrm{l}$, creatine kinase $51 \mathrm{U} / \mathrm{l}$, alanine aminotransferase $22 \mathrm{U} / \mathrm{l}$, aspartate transaminase $28 \mathrm{U} / \mathrm{l}$, alkaline phosphatase $111 \mathrm{U} / \mathrm{l}$, total bilirubin $13.2 \mu \mathrm{mol} / \mathrm{l}$, blood glucose $6.5 \mathrm{mmol} / \mathrm{l}, \mathrm{Na} 130.5 \mathrm{mmol} / \mathrm{l}, \mathrm{K} 4.3 \mathrm{mmol} / \mathrm{l}$ and C-reactive protein $43.9 \mathrm{mg} / \mathrm{l}$. Blood culture was ordered for possible sepsis episode.

Blood cultures were set up. In brief, on positive signal from the BacT/Alert 3D blood culture cabinet obtained $24 \mathrm{~h}$ after incubation, inoculations were made on nutrient agar, blood agar and MacConkey agar plates and incubated at $37^{\circ} \mathrm{C}$. The growth was identified as O. anthropi by the MicroScan WalkAway 96 SI (Dade Behring) as well as by conventional techniques. The strain had the following characteristics: strictly aerobic Gram-negative bacilli, growth was also obtained under $5 \% \mathrm{CO}_{2}$ conditions, no growth under anaerobic conditions, good growth on usual laboratory media after overnight incubation at $37^{\circ} \mathrm{C}$, positive growth at $42^{\circ} \mathrm{C}$, no growth at $4-5^{\circ} \mathrm{C}$, motile, non-lecithinase producer on serum agar, non-pigment producer, non-lactose fermenting, and catalase, oxidase, urease and nitrate positive but citrate was not utilized in Simmons' citrate medium. No acid was formed from glucose in peptone water medium. Only glucose was oxidatively broken down in O-F medium. The strain was clearly differentiated from other related species. In fact, more than 30 characteristics were taken into account in the identification process. Importantly, our strain was found sensitive to colistin $(10 \mu \mathrm{g} / \mathrm{disk}$; Hi-Media) and polymyxin B (300 IU/disk; Hi-Media). Therefore, the possibility of Ochrobactrum intermedium was ruled out. As the strain produced acid from adonitol and dulcitol, the possibility of other related species like Achromobacter xylosoxidans and Achromobacter group B was equally ruled out. Being motile both at $37^{\circ} \mathrm{C}$ and at $20-22^{\circ} \mathrm{C}$, it was easily differentiated from Brucella spp.

The organism was sensitive to ciprofloxacin, levofloxacin, piperacillin/tazobactam and trimethoprim/sulfamethoxazole and resistant to amikacin, cefotaxime, ceftazidime, ceftriaxone, cefepime, gentamicin, imipenem, piperacillin, tetracycline, ticarcillin/clavulanate and tobramycin. It was also resistant to imipenem by the conventional Kirby-Bauer disk diffusion technique on Muller-Hinton agar with no zone of inhibition around a $10-\mu \mathrm{g}$ imipenem disk (Hi-Media) using the $0.5 \mathrm{McF}$ arland standard.

The patient was given cefotaxime and acyclovir empirically. On day 42 , she became fully conscious but still had a fever. On day 45 , her fever resolved completely. The patient made a good recovery with no neurological deficit. On day 54 , she was discharged home.

\section{Discussion}

O. anthropi is often associated with nosocomial infection in debilitated patients, most commonly catheter-associated bacteremia likely due to its ability to adhere to various synthetic materials such as silicone tubing [5]. A Medline search of the term Ochrobactrum anthropi from 1989 to 2006 yielded 145 citations, representing 48 reports of clinical cases of O. anthropi infection. Only 9 reports of $O$. anthropi bacteremia in the pediatric population were found; in 7 of them, bacteremia occurred in immunocompromised children with underlying malignancy or severe disease.

In children, O. anthropi bacteremia usually presents with fever and nonspecific clinical manifestations [6]. The underlying inborn error of metabolism rendered our patient immunocompromised. The patient manifested primary O. anthropi bacteremia with no obvious focus. Of note, throughout her hospital stay, she had had a peripheral venous catheter which was subject to frequent change. It can be speculated that the catheter might have provided a portal of entry to the pathogen or a prior colonization as has been reported with indwelling catheters $[3,5]$.

Although empirical cefotaxime therapy yielded good clinical response, the O. anthropi isolated from her blood was found resistant to $\beta$-lactams (such as cefotaxime and 
ceftriaxone). It is plausible that the good clinical outcome was not due to cefotaxime therapy but due to low virulence and low pathogenicity of the organism [7]. It has been reported that patients with $O$. anthropi infection that were not given any specific treatment made a rapid recovery [8]. It is therefore possible that the favorable outcome of this infection in our patient could be partly related to the nature of the organism.

The imipenem resistance in this strain is a unique finding as to the best of our knowledge it has never been reported before. According to Bailey and Scott [9], O. anthropi is reported to be commonly resistant to all currently available penicillins and cephalosporins but usually susceptible to imipenem. Such a finding was formerly reported by Bizet and Bizet [10] who determined the susceptibility of 13 strains of $O$. anthropi by the agar diffusion method.

In fact, O. anthropi is the name given for 3 (A, C and D) of the $6(\mathrm{~A}-\mathrm{F})$ biotypes of Achromobacter-like strains from clinical material [11]. Recently, imipenem resistance has been found in A. xylosoxidans (a bacterial subspecies to which $O$. anthropi is closely related) isolated from patients hospitalized in the intensive care unit of a Korean tertiary hospital [12]. It is relevant to mention that we not only obtained few imipenem-resistant Alcaligenes $x y$ - losoxidans subspecies xylosoxidans (A. xylosoxidans) isolates from clinical specimens in our hospital, but we also obtained few isolates of imipenem-resistant Pseudomonas aeruginosa. Of note, an imipenem-resistant $A$. $x y$ losoxidans strain was isolated from another patient in the same ward during February 2006 [unpubl. data].

Imipenem has quite often been injudiciously used in treating infections by Gram-negative bacilli globally. It is reasonable to believe that $O$. anthropi has acquired imipenem resistance from either its above racemates or from $P$. aeruginosa. To limit the spread of antimicrobial resistance, we recommend that imipenem should not be used as a first-line drug for treating infections by Gram-negative bacilli. It should be reserved for cases refractory to all antibiotics as is done with vancomycin which is used to treat infections by methicillin-resistant Staphylococcus aureus strains.

\section{Conclusion}

This study reported O. anthropi as a rare nosocomial pathogen that affected a patient who was immunocompromised. O. anthropi showed multidrug resistance.

\section{References}

$>1$ Kettaneh A, Weill FX, Poilane I, Fain O, Thomas M, Herrmann JL, Hocqueloux L: Septic shock caused by Ochrobactrum anthropi in an otherwise healthy host case report. J Clin Microbiol 2003;41:1339-1341.

2 Holmes B, Popoff M, Kiredjian M, Kersters $\mathrm{K}$ : Ochrobactrum anthropi gen nov, sp nov from human clinical specimens and previously known as group Vd. Int J Syst Bacteriol 1988;38:406-416.

-3 Mahmood MS, Sarwari AR, Khan MA, Sophie Z, Khan E, Sami S: Infective endocarditis and septic embolization with Ochrobactrum anthropi: case report and review of literature. J Infect 2000;40:287-290.

4 Ozdemir D, Soypacac Z, Sahin I, Bicik Z, Sencan I: Ochrobactrum anthropi endocarditis and septic shock in a patient with no prosthetic valve or rheumatic heart disease: case report and review of the literature. Jpn J Infect Dis 2006;59:264-265.
5 Alnor D, Frimodt-Moller N, Espersen F, Frederiksen W: Infections with the unusual human pathogens Agrobacterium species and Ochrobactrum anthropi. Clin Infect Dis 1994;18:914-920.

-6 Stiakaki E, Galanakis E, Samonis G, Christidou A, Maraka S, Tselentis Y, Kalmanti M: Ochrobactrum anthropi bacteremia in pediatric oncology patients. Pediatr Infect Dis J 2002;21:72-74.

7 Yu WL, Lin CW, Wang DY: Clinical and microbiologic characteristics of Ochrobactrum anthropi bacteremia. J Formos Med Assoc 1998;97:106-112.

8 Galanakis E, Bitsori M, Samonis G, Christidou A, Georgiladakis A, Sbyrakis S, Tselentis Y: Ochrobactrum anthropi bacteraemia in immunocompetent children. Scand J Infect Dis 2002;34:800-803.

9 Achromobacter, Rhizobium, Ochrobactrum and similar organisms; in Forbes BA, Sahm DF, Weissfeld AS (eds): Bailey \& Scott's Diagnostic Microbiology, ed 11. St Louis, Mosby Inc, 2002, pp 399-405.
10 Bizet C, Bizet J: Comparative susceptibility of Ochrobactrum anthropi, Agrobacterium tumefaciens, Alcaligenes faecalis, Alcaligenes denitrificans subsp. denitrificans, Alcaligenes denitrificans subsp. xylosidans and Bordetella bronchiseptica against 35 antibiotics including $17 \beta$-lactams. Pathol Biol (Paris) 1995;43:258-263.

11 Holmes B, Dawson CA: Numerical taxonomic studies on Achromobacter isolates from clinical material; in Leclerc $\mathrm{H}$ (ed): Gram-Negative Bacteria of Medical and Public Health Importance. Paris, Colloque INSERM, 1983, pp 331-341.

- 12 Shin KS, Han K, Lee J, Hong SB, Son BR, Youn SJ, Kim J, Shin HS: Imipenem-resistant Achromobacter xylosoxidans carrying blaVIM-2-containing class 1 integron. Diagn Microbiol Infect Dis 2005;53:215-220. 